\title{
EL PENSAMIENTO DE NIETZSCHE EN LA CONSTRUCCIÓN DE LA ESTÉTICA DEL FUTURISMO Y DE LA PINTURA METAFÍSICA
}

\author{
Nietzsche's Thought in the Aesthetics Development of \\ Futurism and Metaphysical Art \\ María Olga Sáenz \\ Instituto de Investigaciones Estéticas, UNAM (México)
}

RESUMEN: En el siglo XIX, Francia desplazó a Italia de su secular trayectoria como centro generador de las artes. Frente a este hecho, tanto Filippo Tommaso Marinetti, creador del Futurismo italiano, como Giorgio de Chirico, de la Pintura Metafísica, aportaron su particular poética al arte moderno europeo. Ambos recibieron una influencia decisiva del pensamiento filosófico de Friedrich Nietzsche: Marinetti conceptualizó la creación artística bajo la premisa «arte=vida» intentando trascender la crisis del mundo de Occidente. De Chirico construyó su obra pictórica trastocando su significado original, con el fin de discernir su segunda apariencia, dentro de un ámbito espectral, metafísico, para representar con metáforas plásticas «el eterno retorno».

Palabras Claves: De Chirico - Pintura metafísica - Futurismo - Marinetti

AвSTRACT: During the nineteenth century, France replaced Italy as the generator center of the arts, after a centuries-long tradition. Given this fact, both Filippo Tommaso Marinetti, founder of Italian Futurism, and Giorgio de Chirico, creator of Metaphysical Painting, brought their unique poetics into European modern art. Both received a decisive influence from Friedrich Nietzsche's philosophical thought: Marinetti conceived artistic creation under the motto «art=life», attempting to transcend the crisis of the Western world. De Chirico constructed his paintings subverting their original meaning, in order to discern their second appearance, in a spectral and metaphysical field, to represent with visual metaphors «the eternal return».

Key Words: De Chirico - Metaphyscal Art - Futurism - Marinetti

«Las mayores tendencias del impresionismo en las artes plásticas se observan entre los pueblos menos filosóficos y en las épocas transitorias entre uno y otro periodo de esfuerzo metafísico».

Giorgio de Chirico ${ }^{1}$

\section{ANTECEDENTES}

Las primeras vanguardias artísticas surgieron en Francia en las últimas décadas del siglo XIX y las primeras del siglo Xx, como respuesta a los rígidos cánones

1. Cf. O. Sáenz, Giorgio de Chirico y la pintura metafísica, México: Universidad Nacional Autónoma de México, 1990, pp. 69-72. 
académicos del arte oficial que se alió con los intereses del poder monárquico y gubernamental. Como respuesta al autoritarismo institucional, el grupo de rechazados de los salones oficiales se propuso liberarse y construir un lenguaje icónico que respondiera a los retos que exigía la era moderna.

Este periodo coincidió con la toma de poder de Napoleón III, quien continuó las empresas imperiales de Napoleón I, intentando extender sus dominios hasta los territorios de China y la Cochinchina, además de iniciar un paulatino control del continente americano, con la presencia de Maximiliano de Habsburgo en la República Mexicana. Asimismo, propició el desarrollo de un ambicioso programa modernizador para controlar las revueltas populares al interior de París y situarse como paradigma de la gran metrópoli tanto en el ámbito económico, como en el político y el cultural. Estos hechos favorecieron un vigoroso comercio global, además de un intercambio que propició la comunicación intercultural con los países asiáticos y africanos. Sin embargo, lo que trascendió con vigor de aquel periodo histórico lo resume el pensamiento de François Guizot, quien definió Francia como el país que conformó el perfil de la civilización europea basado en la libertad.

Las primeras vanguardias artísticas —el impresionismo, el neoimpresionismo y el postimpresionismo- encontraron un ambiente propicio para expresarse con nuevos lenguajes icónicos. Fue Édouard Manet el artista que marcó un hito en el devenir de las artes, al crear tanto un nuevo discurso visual con el Almuerzo sobre la hierba, pintando una escena a plein air, como un innovador lenguaje lumínico; sin embargo, lo más notable fue que motivó de manera indirecta a los jóvenes pintores a la búsqueda de nuevas resoluciones plásticas y, con ello, a la consolidación del movimiento impresionista, caracterizado por el uso de una técnica rápida basada en la descomposición de los colores para aprehender la transparencia de la atmósfera. Cézanne, con mayor autonomía, legó a los cubistas un acucioso estudio sobre la estructura volumétrica que desencadenó una revolución en la representación de la imagen al trastocar la tradición del arte figurativo y abrir brecha a la abstracción.

París fue el escenario que auspició los sueños de la utopía de la modernidad, abruptamente interrumpidos por la primera conflagración mundial, y qué mejor que sea el propio Walter Benjamin quien ilustre el origen y desarrollo de la era de «la pompa y el boato parisino». La mayor parte de las arcadas de París surgieron en los quince años posteriores a 1822. La primera condición para su emergencia fue el auge del comercio textil. Asomaron los magasins de nouveautés, primeros establecimientos que guardaban en sus locales un gran surtido de mercancías... El inicio de la construcción en hierro fue la segunda condición para el surgimiento de las arcadas... Estas relaciones pueden discernirse en la utopía ideada por Fourier. Su origen más profundo yace en la aparición de las máquinas... Con la construcción en hierro, la arquitectura empezó a rebasar el arte; lo mismo pasó con los dioramas respecto a la pintura... Las exposiciones mundiales fueron lugares de peregrinaje al fetiche de la mercancía ${ }^{2}$.

Frente al engolosinamiento del «fetiche de la mercancía», pareciera que la burguesía fortalecida por la cultura del capitalismo olvidara la Revolución de 1789,

2. W. Benjamin, París, capital del siglo XIX, trad. y notas de M. González y J. E. Pacheco, México: Imprenta Madero, 1971, pp. 13-34. 
así como las revueltas populares de 1831 a 1871, desde el alzamiento de Lyon hasta la Comuna. Los obreros fueron marginados del oropel de la modernidad. La soledad del trabajador manual fue excepcionalmente acompañada por Rimbaud y Courbet, quienes «se pronunciaron a favor de la Comuna. El incendio de París fue la más adecuada conclusión de la obra destructora de Haussmann» ${ }^{3}$.

La misma suerte corrieron los artistas vanguardistas, quienes pronto fueron discriminados por los defensores del arte oficial, como el crítico de arte Louis Leroy, quien con escarnio y mordacidad denominó al movimiento «impresionista», después de observar la obra de Claude Monet Impresión, salida del sol. A pesar de ello, fueron literatos como Émile Zola, Gabriel-Albert Aurier -cofundador del Mercure de France-, Stéphane Mallarmé, Louis-Émile-Edmond Duranty, entre otros muchos, quienes defendieron y crearon una teoría artística sobre los primeros movimientos de vanguardia, eminentemente urbanos y franceses, cuyas raíces se vinculan de manera directa con los avances técnicos y científicos; ${ }^{4}$ de ahí que su poética fuera esencialmente pragmática y acorde con la vida moderna de la ciudad cosmopolita.

\section{ITALIA Y LAS VANGUARDIAS ARTÍSTICAS: EL FUTURISMO Y LA PINTURA METAFÍSICA}

Si bien Italia fue desplazada de su secular trayectoria como centro generador de los principales movimientos artísticos, fueron precisamente dos artistas cuyas familias eran de origen italiano, pero que por razones de trabajo del progenitor respectivo nacieron fuera de Italia, quienes, de manera independiente, coincidieron en el hecho de retribuirle a la cultura italiana el peso rector de las artes en la era moderna. Fue así que el lugar de nacimiento de Filippo Tommaso Marinetti (1876-1944) se vio determinado por su padre Enrico, quien desempeñaba como abogado en Alejandría, Egipto. Una circunstancia similar ocasionó que Giorgio de Chirico naciera en Volos, Grecia, pues su padre Evaristo, ingeniero ferroviario, fue el responsable de la construcción del ferrocarril de Tesalia.

Tanto Marinetti, creador de la vanguardia futurista, como De Chirico, de la pintura Metafísica, recibieron la influencia de las culturas francesa y alemana, pero concordaron en la necesidad de identificarse preferentemente con la tradición itálica, elección que se vio claramente reflejada en la participación activa de ambos artistas en el frente de combate durante la primera guerra mundial.

3. Ibid.

4. Tal fue el caso de los avances en la óptica logrados por los estudios de Fraunhofer, quien examinó el espectro de la luz solar con un diseño más preciso de sus instrumentos de observación; de las definiciones sobre la teoría ondulatoria de Fresnel; de los avances en el campo fotográfico de Niépce y Daguerre, quienes favorecieron la elaboración de cámaras que permitieron aprehender el instante en movimiento para representarlo en obras pictóricas; además del desarrollo del arte cinematográfico con Muybridge, quien posibilitó reproducir las imágenes en movimiento al utilizar un mecanismo electromagnético en su zoopraxiscopio, sin olvidar a Maxwell, pues con el electromagnetismo fue capaz de formular la teoría de la luz que unificaba sus componentes eléctricos y magnéticos. Cf. R. J. Weiss, Breve storia della luce. Arte e scienza dal Rinascimento a oggi, trad. de E. Maurutto, Bari: Dedalo, 2005, pp. 65-148. 
Para Marinetti, como ya había declarado en el manifiesto fundacional de 1910, la guerra era la «única higiene del mundo». Éste fue un argumento central en su poética, cargada de un fuerte contenido mítico y estético, al definir la vida como acompañada de agresión, y a la paz universal como decrepitud y agonía de las razas. ${ }^{5} \mathrm{Su}$ compromiso con Italia lo reforzó en el documento donde explica las primicias fundamentales del futurismo, al afirmar que es correligionario en política «quien ama el Progreso de Italia más que de sí mismo» ${ }^{6}$. Para De Chirico, el compromiso bélico fue también la oportunidad de mostrar sus raíces familiares y nacionales a favor de la Italia moderna, heredera de las glorias del gran imperio romano ${ }^{7}$.

En el campo artístico, tanto Marinetti como De Chirico construyeron su particular poética vanguardista logrando trascender dentro de los más importantes movimientos culturales de la época. El primero fundamentó su tesis del futurismo en la conjunción de «arte-vida» como la ecuación que resume el poder y la fuerza del arte en la propia existencia de los hombres para cambiar y trasformar los factores que impiden el progreso y la evolución humana. Para el autor, es futurista: «Aquel que ama la vida, la energía, la alegría, la libertad, el progreso, el valor, la innovación, la practicidad, la velocidad».

En contraste con esta veneración por la vorágine de la velocidad que marcó la era moderna, De Chirico y su hermano Andrea, quien cambió de nombre por Alberto Savinio, definieron la pintura metafísica como «el romanticismo de lo misterioso", la representación de imágenes que se construyen trastocando su significado original, con el fin de discernir su segunda apariencia, dentro de un ámbito espectral, metafísico. Se trata pues, de representar el «no sentido de la vida», que como tal se puede trasmutar en arte ${ }^{8}$.

Fueron dos maneras aparentemente antagónicas de expresar sus poéticas, ya que el futurismo se regía por una concepción vitalista y sus creadores se identificaron con el ritmo de las ciudades industriales alimentando el mito del progreso y de la velocidad, además de crear un nuevo panteón habitado por las máquinas como nuevos dioses de la modernidad. Mientras que para los pintores metafísicos, la aprehensión de elementos compositivos mediante recursos conceptuales propios les permitió proyectar nuevos parámetros espaciales y temporales. No obstante la aparente polarización en la retórica de la imagen, en ambas vanguardias existe una convergencia teórica por la identificación de la poética de la «no razón» y de la «sin razón», basada en la filosofía irracional de Schopenhauer, pero sobre todo en Friedrich Nietzsche.

5. F. T. Marinetti, «En este año futurista», 1914.

6. F. T. Marinetti, "Qué es el futurismo. Nociones elementales», 1914.

7. Marinetti sufrió la muerte de artistas simpatizantes con el futurismo, como el arquitecto Antonio Sant'Elia, quien falleció en el frente de batalla, y la pérdida irreparable de Umberto Boccioni, al caer de un caballo en 1916. Giorgio de Chirico y los pintores que se unieron a su poética, como Carlo Carrà, Filippo de Pisis, Giorgio Morandi, entre otros, se refugiaron en el hospital Villa Seminario, en Ferrara, después de una fuerte crisis del fundador de la escuela metafísica.

8. Cf. O. Sáenz, Giorgio de Chirico, cit., pp. 23-25. 


\section{PRESENCIA DE LA FILOSOFÍA IRRACIONAL EN LA PINTURA METAFÍSICA: ARTHUR SCHOPENHAUER}

«Cada cosa tiene dos aspectos: uno corriente, que vemos casi siempre y que ven los hombres en general; el otro espectral o metafísico, que no pueden ver más que raros individuos en momentos de clarividencia y de abstracción metafísica».

Giorgio de Chirico 9

Desde su etapa juvenil, Giorgio de Chirico se percató de la existencia de la realidad metafísica, ya que durante sus años formativos en la Academia de Múnich tuvo la oportunidad de adquirir, además de una sólida preparación académica, el conocimiento del arte simbolista del suizo Arnold Böcklin, y del alemán Max Klinger. Al primero debe su acercamiento al signo mitológico griego, que reforzó la remembranza de su etapa infantil y juvenil. ${ }^{10}$ Con el segundo, apreció la posibilidad de representar «el no sentido de la vida», utilizando elementos de la vida contemporánea para revelar la poética metafísica. Tal es el caso de la serie de aguafuertes Paráfrasis sobre el encuentro de un guante perdido, con la que Max Klinger narra una experiencia autobiográfica por medio de las dolorosas peripecias que sufrió el guante de una dama —símbolo del objeto de deseohasta que finalmente venció el amor ${ }^{11}$. De Klinger, opinó de Chirico, «ha sido el artista moderno por excelencia» ${ }^{12}$.

Además, esta connotación simbólica lo acercó al lenguaje metafórico para representar con imágenes su pensamiento teórico, eminentemente enunciativo, el «no sentido del mundo», la «segunda apariencia de las cosas», el mundo metafísico, que sólo se puede conocer dentro de un proceso de revelación. Esta premisa se origina en el pensamiento de Schopenhauer, quien la desarrolló en su obra capital El mundo como voluntad y representación, donde coincidió con Platón en la importancia esencial de la Idea, «mientras que a las cosas existentes en el tiempo y en el espacio, que componen el mundo real para el individuo, no les concedía más que una existencia aparente de ensueño» ${ }^{13}$.

De Chirico coincide con el filósofo al afirmar que el mundo es una representación que se encuentra ordenada por el espacio, el tiempo y la causalidad. De tal suerte que no se puede distinguir claramente entre la vigilia y el sueño, ya que sólo en este último no existe un hilo conductor coherente y continuo:

La vida y los ensueños son hojas de un mismo libro. Su lectura de conjunto se llama vida real. Pero cuando las horas de lectura habitual (el día) terminan, y las

9. G. de Chirico, «Locura y arte», en O. Sáenz, Giorgio de Chirico, cit., pp. 65-66.

10. A manera de ejemplo, comparemos la obra titulada Batalla de centauros de Arnold Böcklin (1872-1873, Basilea, Kunstmuseum) con la ejecutada por Giorgio de Chirico, Lucha de centauros (1909, Roma, Galería Nacional de Arte Moderno); otro ejemplo: El enigma del oráculo (1910) de Giorgio de Chirico y Ulises y Calipso (1882) de Arnold Böcklin; o, por último, Tritón y Sirena (1909) de Giorgio de Chirico y Tritón y Nereida (1873-1874, Mónaco, Galería Schack) de Arnold Böcklin.

11. «En la serie de aguafuertes Paráfrasis sobre el encuentro de un guante perdido, Klinger agrega al sentido romántico moderno una fantasía de soñador y de narrador, tenebroso e infinitamente melancólico» O. Sáenz, Giorgio de Chirico, cit., pp. 81 y 82.

12. G. de Chirico, «Arnoldo Böcklin», en O. Sáenz, Giorgio de Chirico, cit., p. 85.

13. A.Schopenhauer,Elmundocomovoluntady representación,México: Porrúa,2003,pp.192-195. 
de descanso han llegado, nos dedicamos a hojear sin orden ni concierto aquí y allá [...] también nuestra vida es una hoja suelta en el libro del universo [...] por lo tanto tendremos que convenir con los poetas en que la vida es un largo sueño ${ }^{14}$.

A esta definición Schopenhauer añade que en ambos estados se experimenta la ilusión del mundo tangible. En cuanto a la voluntad, "hemos llegado a la afirmación de que la esencia del mundo es la voluntad y de que todos sus fenómenos no son más que su voluntad objetivada». Sólo la voluntad le revela al individuo el mecanismo interno de su esencia, de su conducta, de sus movimientos, con lo cual podemos intentar dirigir y controlar nuestra existencia; ese intento fallido "para los más, la vida sólo es una continua lucha por la existencia, con la certidumbre de una derrota final» ${ }^{15}$.

Como posibilidad de liberación del dolor, del miedo y de la inseguridad, Schopenhauer recomienda al ser humano el gozo estético que debe estar acompañado del conocimiento objetivo en su forma más pura y perfecta, desligado de la voluntad, «es un manantial vivo de gozo espiritual y que sólo por esto ya contribuye considerablemente al gozo estético». El filósofo considera que, de todas las representaciones del mundo material en imágenes artísticas, la que alcanza un grado de dificultad suma es la figura humana, ya que tiene «un sistema combinado de partes de la mayor complejidad, cada una de las cuales está subordinada al todo, pero posee también una idea propia, vita propia» ${ }^{16}$.

Al analizar las artes, Schopenhauer se detiene en la escultura para discernir sobre la belleza como fin supremo de su creación, «juntamente con la gracia, ama el desnudo y sólo tolera las vestiduras cuando éstas no ocultan las formas» ${ }^{17}$. De Chirico retoma el pensamiento del filósofo para inducir al espectador a la experiencia estética, perdiendo la conciencia de sí mismo, para adquirir conocimiento de los objetos intuidos.

Schopenhauer, que mucho sabía de tales asuntos, aconsejaba a sus coterráneos no poner las estatuas de sus hombres ilustres sobre columnas y pedestales demasiado altos, sino más bien posarlas sobre zócalos bajos, «como se hace en Italia —decía- donde algunos hombres de mármol parecen encontrarse al mismo nivel que los transeúntes y caminar con ellos» ${ }^{18}$.

De Chirico aprehende la esencia del pensamiento filosófico que concede al arte una propiedad liberadora y consoladora, y utiliza la pintura para darle, mediante elementos comunes, un significado metafísico. Afirma que, al conocer el alfabeto metafísico en su calidad de genio,

sabe qué goces y qué colores se encierran en cada uno de los elementos compositivos: los límites de estos signos constituyen para nosotros una especie de código moral y estético de las representaciones, y además, con clarividencia, construimos en pintura una nueva psicología metafísica de las $\operatorname{cosas}^{19}$.

14. Ibid., pp. 30-35.

15. Ibid., pp. 121-122.

16. Ibid., pp. 228-234.

17. Ibid., p. 237.

18. G. de Chirico. «Estética metafísica», en O. Sáenz, Giorgio de Chirico, cit., pp. 67 y 68.

19. Ibid., pp. 67-69. 


\section{PRESENCIA DE FRIEDRICH NIETZSCHE EN LA METAFÍSICA DECHIRICHEANA}

La connotación liberadora y consoladora que Schopenhauer dio al arte la retomó Nietzsche reafirmando su tesis al coincidir que, frente al dolor que tiene que afrontar el ser humano en su largo caminar, sólo el arte le permite un estado de gozo estético. En El origen de la tragedia, el filósofo nacido en Röcken define al mundo dentro de una concepción trágica y se refiere a la tragedia griega de la etapa presocrática como el ejemplo contundente de la embriagadora aceptación de la vida, en la que el coro ocupa un lugar preeminente dentro de su disquisición estética. Otorga a la música el origen caótico del mundo, y «lo trágico es concebido como principio cósmico» ${ }^{20}$.

Para De Chirico, los instantes en que se pueden develar los misterios de los objetos que nos rodean nos llevan a conocer el lado metafísico de la vida, que podría calificarse dentro un proceso anormal. «Creo que en cada persona pueden rastrearse tales momentos anormales, y cuanto más felices cuando se manifiestan en individuos dotados de talento creativo y de clarividencia.» Es la experiencia propia del pintor o del escritor metafísico, quien después de un acto de revelación puede plasmar o narrar en la obra de arte la segunda apariencia de la vida. «Tal es el caso de Julio Verne, que escribió novelas de viajes y de aventuras y que pasa por un escritor ad usum puerorum. Pero quién mejor que él supo adivinar la metafísica de una ciudad como Londres en sus casas, sus calles, sus clubes, sus plazas, sus jardines $»^{21}$.

Este origen cognoscitivo del pintor tiene su referencia en la reflexión del filósofo alemán, quien señala que el origen del drama no involucra al espectador pasivo que observa a los actores disfrazados para engañarlos: «no, antes bien, en que el hombre esté fuera de sí y se crea a sí mismo transformado y hechizado. En el estado del 'hallarse-fuera-de-sí', en el éxtasis...", para transformarlos en otro $\operatorname{ser}^{22}$. En el proceso de conocimiento que comenta De Chirico, para transmutar al ser humano después del éxtasis metafísico, impera la intuición, que es adivinación.

Nietzsche concibió la creación artística como esencialmente intuitiva, compuesta por dos fuerzas antitéticas pero complementarias, pues se correría un gran peligro si el principio básico optimista-apolíneo quisiera aniquilar a lo dionisíaco: «Aquí esa voluntad intervino en seguida con su fuerza curativa natural, para dar la vuelta a ese estado de ánimo negador: el medio de que se sirve es la obra de arte trágica y la idea trágica. Su propósito no podía ser en modo alguno sofocar el estado dionisíaco, y, menos aún, suprimirlo»; ya que su fuerza se desbordaría y se abriría paso por «todas las venas de la vida» ${ }^{23}$.

Apolo, así, representa una visión ideal, expresa el sentido de las cosas con equilibrio y moderación. Dioniso, por el contrario, representa la fuerza instintiva, desmesurada, del frenesí sexual, es ebriedad creativa, pasión, en suma, caos. En arte, Apolo representa el arte figurativo, y Dioniso para el filósofo es el inspirador del arte no figurativo de la música:

20. Cf. E. Fink, La filosofía de Nietzsche, Madrid: Alianza, 1996, pp. 26 y 27.

21. G. de Chirico. «Sobre el arte metafísico», en O. Sáenz, Giorgio de Chirico, cit., pp. 63 y 64.

22. NT, Madrid: Alianza, ${ }^{4} 1979$, pp. 201 y 202

23. Ibid., pp. 244 y 245. 
En la esfera del arte estos nombres representan antítesis estilísticas que caminan una junto a otra, casi siempre luchando entre sí y que sólo una vez aparecen fundidas, en el instante del florecimiento de la voluntad helénica, formando la obra de arte de la tragedia ática ${ }^{24}$.

Con base en el concepto nietzscheano, De Chirico confirma la trascendencia del arte en el ensayo titulado «El sentido arquitectónico del arte», en el que explica la importancia simbólica de los diferentes elementos arquitectónicos que acompasan las metáforas filosóficas. Los pórticos griegos, enmarcando el paisaje, adquieren mayor valor metafísico: «El poeta primitivo, Homero, por ejemplo, que canta el espacio infinito, el mar altisonante y los abismos del cielo fecundo en númenes». Las perspectivas arquitectónicas se revisten de misterios:

La obra de arte es el drama cósmico y vital que envuelve a los hombres y los constriñe dentro de sus espirales, donde pasado y futuro se confunden, donde los enigmas de la existencia, santificados por el soplo del arte, se despojan del aspecto enmarañado y aterrador que fuera del arte el hombre se imagina, para revestir la apariencia eterna, tranquila y consoladora de la construcción genial ${ }^{25}$.

La crítica que De Chirico hace a la pintura del seiscientos es precisamente que el pintor perdió el interés por buscar: «Ha perdido el instinto del viajero y del explorador». Ha descuidado la herencia de los hombres del pasado. «La figura humana pierde todo poder expresivo, toda espectralidad, todo valor espiritual». El desinterés por los valores metafísicos lo lleva al verismo, cuyas muy deplorables consecuencias hoy resultan evidentes para todos aquellos que tienen los ojos limpios y la mente clara».

Esta reflexión rememora el pensamiento nietzscheano, cuando evoca la sabiduría milenaria para explicar el momento de la inspiración en la revelación:

Todo acontece de manera sumamente involuntaria, pero como en una tormenta de sentimientos de libertad, de incondicionalidad, de poder, de divinidad... La involuntariedad de la imagen, del símbolo es lo más digno de atención; no se tiene ya concepto alguno; lo que es imagen, lo que es símbolo, todo se ofrece como la expresión más cercana, más exacta, más sencilla... Ésta es mi experiencia de la inspiración; no tengo duda de que es preciso remontarse milenios atrás para encontrar a alguien que tenga derecho a decir «es también la mía» ${ }^{26}$.

\section{ALBERTO SAVINIO Y ANADIOMÉNON O PRINCIPIOS DE VALORACIÓN DEL ARTE CONTEMPORÁNEO}

Alberto Savinio (originalmente llamado Andrea de Chirico) fue coautor junto con su hermano Giorgio de la teoría metafísica. En él también se advierte la presencia del pensamiento del filósofo alemán en la construcción de sus ideas

24. Ibid., p. 230.

25. G. de Chirico, «El sentido arquitectónico en la pintura antigua», en O. Sáenz, Giorgio de Chirico, cit., pp. 72-75.

26. EH, Madrid: Alianza, 1988, pp. 97 y 98. 
estéticas. Al referirse a lo fantásmico, lo explica como «fenómeno incipiente de representación; génesis de todos los aspectos». Y cuando aplica esta categoría al ser humano, agrega Savinio, es: «estado inicial del momento de descubrimiento, cuando el hombre se encuentra en presencia de una realidad desconocida para él anteriormente». Savinio asegura que «el mundo es - como Venus- anadioménon: pues continuamente surge de un mar que lo gesta en un alumbramiento misterioso, que suscita un dios novel ${ }^{27}$.

En el mismo ensayo refiere el origen de la palabra metafísica, en relación con el arte y la pintura. Este vocablo utilizado por la tratadística filosófica para dar cuenta de un balance explícitamente físico, posteriormente fue retomado por la teología y, por fin, encontró por vez primera en Nietzsche una razón espiritual libre: «todo aquello que prolonga al ser de la realidad, además de los aspectos burdamente evidentes de la realidad misma ${ }^{28}$. Para Savinio, la metafísica concebida dentro de esta connotación está limitada geográficamente:

Después de su inmenso florecimiento en Grecia, la filosofía espiritualista emigra hacia Occidente para volver a florecer. (No olvidemos la filosofía -llamémosla napolitana- de Vico, Campanella, Bruno...). No llega a Francia (¿de qué valieron las lecciones de Giordano Bruno para las universidades de Tolosa, de París...?), pero la vemos expandirse por Alemania hasta llegar a su fase extrema (Nietzsche) en la fórmula: metafísica ${ }^{29}$.

Dentro de esta categoría metafísica, Savinio sólo concibe la obra de dos pintores: la de su hermano Giorgio de Chirico y la de Carlo Carrà, ya que poseen plenitud de representación, entendida como «la necesidad espiritual en sus límites plásticos; potencialidad expresiva en la espectralidad», que "es la verdadera esencia espiritual y sustancial de todo aspecto... es el fin máximo del arte». Ironía: «que en pintura tiene preponderancia, y es el momento que se percibe la original precisión de la naturaleza, y provoca una reacción sutilísima que en el artista se puede llamar pudor»; al trastocar «los aspectos terriblemente claros que el percibe $»^{30}$.

El escrito que Savinio tituló «Primeros ensayos de filosofía de las artes I» lo dedicó a la inmortal Mnemosine, «Diosa olvidada, la Memoria». En él expone la esencia misma de su pensamiento, que encuentra sus raíces en la filosofía nietzscheana. Su lamento profundo lo centra en el olvido de la diosa de la Memoria, «la pía y consoladora Memoria ya no ve las manos que se levantan hacia ella en invocación». Abandona a los hombres en un laberinto sin destino. "Mientras tanto corre la locura», advierte el autor, e invade las naciones con la locura de la desmemoria. "Quedan pocos que saben decir aún ayer y mañana» ${ }^{31}$.

En la segunda parte de Así habló Zaratustra, Nietzsche desarrolla una de sus tesis fundamentales: «la voluntad de poder». Concede al hombre la libertad de crear un nuevo horizonte «que juega creando», que construye valores con una voluntad renovada.

27. A. Savinio, «Anadioménon. Principio de valoración del arte contemporáneo», en O. Sáenz, Giorgio de Chirico, cit., pp. 108-119.

28. Ibid.

29. Ibid, p. 114.

30. Ibid.

31. A. Savinio, «Primeros ensayos de filosofía de las artes I, II y III», en O. Sáenz, Giorgio de Chirico, cit., pp. 125-133. 
Dios es un pensamiento que vuelve torcido todo lo derecho y que hace voltearse a todo lo que está de pie. ¿Cómo? ¿Estaría abolido el tiempo, y todo lo perecedero sería únicamente mentira? [...] iMalvadas llamo, y enemigas del hombre, a todas esas doctrinas de lo Uno y lo Inmóvil y lo Saciado y lo Imperecedero! [...] Del tiempo y del devenir es de lo que deben hablar los mejores símbolos; iuna alabanza deben ser y una justificación de todo lo perecedero! ${ }^{32}$.

Para Savinio, la Memoria es la generadora del arte. Ya que si la creación artística no deriva de la Memoria el arte es «innoble — plebeyo- restringido y lleno de tedio: vano como los sueños». Para Savinio y para su hermano Giorgio, «el arte no tiene ningún punto de acercamiento con los sueños», ya que los sueños no tienen pasado ni porvenir, por lo tanto carecen de memoria. La fantasía del sueño proviene del presente, por lo tanto es vana. Ésta fue la causa fundamental por la que Giorgio de Chirico no aceptó el apelativo de "padre del surrealismo", que con tanto entusiasmo y veneración le asignó André Breton.

En la segunda parte del ensayo, Savinio expone sus conceptos sobre el arte metafísico para nominar «la cualidad íntima, la sustancia lírica de las cosas». Por último, aclara que «las artes no se valen de las cualidades materiales y tangibles de las cosas, sino más bien de la impalpable, pero más íntima y profunda: se valen de la cualidad metafísica de las cosas» ${ }^{33}$.

Savinio concluye la trilogía sobre el tema con «La inmovilidad terrestre, inspiradora de las artes plásticas». Las artes se inspiran en el tiempo, el movimiento, el devenir, elementos que se suceden en la vida. Esta circunstancia de permanencia en las artes nos comunica estabilidad, frente al destino efímero que conlleva el movimiento reflejando transitoriedad y, por lo tanto, inseguridad y finitud. De ahí que el hombre busque la permanencia como símbolo de eternidad. «Únicamente ésta ha de ser la fuente psicológica de donde los hombres han extraído el concepto de la inmortalidad y, [la hipótesis] de la vida futura» ${ }^{34}$.

En suma, fue durante la etapa florentina que el propio de Chirico declaró haber pintado «los cuadros más profundos que existen», la misma en que el pintor estudió la filosofía de Schopenhauer y de Nietzsche. La decisiva influencia que el pintor recibió de la estética irracional lo podemos constatar en sus metáforas plásticas: su Autorretrato de 1911, con la leyenda en latín «Et quid amabo nisi quod aenigma est?» (¿qué voy a amar si no es el enigma?), y la obra titulada L'énigme de l'heure (1911), donde el proceso de revelación metafísica queda plasmado con un cúmulo de referencias a los conceptos nietzscheanos, como la voluntad de poder en la estructura de la vida. Además, el transcurrir del tiempo queda simbolizado como cauce de la voluntad de poder, representado en el reloj que mimetiza el lapso, que a su vez da cauce al eterno retorno en las aguas de la fuente. La memoria, "la inmortal Mnemosine», origen del saber metafísico, queda eternizada en la perspectiva que forma el pintor con la representación de diversos elementos arquitectónicos, marcados esencialmente por el juego de las arcadas, las cuales custodian los enigmas. La poética plástica de Giorgio de Chirico

32. Za, Madrid: Alianza, 2003, pp. 131-133.

33. A. Savinio, «Primeros ensayos de filosofía de las artes II», cit., pp. 128-131.

34. A. Savinio, "Primeros ensayos de filosofía de las artes III», cit., pp. 131-133. 
alcanza la fuerza de la perfección terrenal con la aparente transmutación del espacio y del tiempo en el signo metafísico.

La aparente polarización de la vertiente metafísica se debió al futurismo italiano, desde cuyo primer manifiesto de 1909 su fundador, el poeta Filippo Tommaso Marinetti, lanzó frases incendiarias «exaltando el movimiento agresivo», «la belleza de la velocidad» y la destrucción de la cultura del pasado; glorificando la guerra; en suma, exaltando la máquina como dios de la era industrial. No obstante los planteamientos supuestamente antagónicos entre ambas vanguardias artísticas, tanto De Chirico como Savinio adoptaron el maniquí como metáfora plástica o literaria originaria. En la obra temprana de Marinetti, la novela Mafarka el futurista, de 1909, representa la figura del hombre-máquina, del maniquí liberado de los sentimientos amorosos: «yo quiero vencer la tiranía del amor, la obsesión de la mujer única, el gran claro de luna romántico que baña la fachada del burdel». Aquí un fragmento del Drama de la ciudad meridiana. Por la gracia de los fantasmas, en el que Savinio rememora la poética marinettiana:

Entra un señor, con levita de ministro. En lugar de la cabeza que le falta, lleva una pequeña bandera plantada sobre una antena de acero. Tiene tres piernas rígidas, inarticuladas, inflexibles, como las patas de un trípode fotográfico. Patina sobre rueditas metálicas, que rechinan horriblemente.

Llegado a la mitad de la placa de mármol, desabrocha su levita, su chaleco, luego un tercer saco que abriéndose, descubre dos alas de carne viva, y los detalles anatómicos del tórax con el juego de los órganos.

El señor hurga en sus pulmones: saca un corazón enorme, rojo como una morcilla hinchada de sangre... ${ }^{35}$.

\section{LA FILOSOFÍA IRRACIONAL EN LA POÉTICA DEL FUTURISMO ITALIANO}

«Nosotros afirmamos que la magnificencia del mundo se ha enriquecido con una belleza nueva: la belleza de la velocidad. Un automóvil de carreras con su toldo adornado de gruesos tubos semejantes a serpientes de aliento explosivo [...] un automóvil rugiente, que parece correr bajo la metralla, es más bello que la Victoria de Samotracia».

Filippo Tommaso Marinetti ${ }^{36}$

Las premisas provocadoras que Marinetti lanzó en su manifiesto fundacional (1909) tenían como fin mover las conciencias anquilosadas de la sociedad moderna, afectada por falsos prejuicios religiosos que exaltaban el temor a Dios y por los convencionalismos de una moral hipócrita, que dieron como resultado la decadencia cultural de Occidente. Esta visión de la vanguardia hunde sus raíces en las premisas de Nietzsche, quien defendió el espíritu dionisíaco como la fuerza controladora del timón de la vida: «es el puente que lleva a la psicología del

35. A. Savinio, «Drama de la ciudad meridiana», en O. Sáenz, Giorgio de Chirico, cit., pp. 137139.

36. F. T. Marinetti, «Fundación y manifiesto del futurismo», en O. Sáenz, El futurismo italiano, México: Universidad Nacional Autónoma, 2010, pp. 89-95 
poeta trágico [...]. Para más allá del espanto y la compasión, ser nosotros mismos el eterno placer del devenir - ese placer que incluye en sí también el placer del destruir...." ${ }^{37}$. El poeta italiano coincide en esta dualidad de la «creación-destrucción» al referirse con vehemencia a la guerra como entidad mística que se vincula con la aristocracia del espíritu. De tal suerte que, al compartir como sujeto trágico de la historia el placer del devenir, conlleva también el deber de destruir en su carácter de ser heroico, asumiendo el espíritu futurista. En el manifiesto «Matemos el claro de luna», el autor define el movimiento futurista como un viaje de iniciación, en el que sus protagonistas dejan atrás «el viejo sol europeo», para escapar de los tristes habitantes de Parálisis y de Podagra, defensores de la burguesía capitalista, exaltando la guerra como elemento purificador:

—iCobardes! — grité, volteándome hacia los habitantes de Parálisis, amontonados a nuestros pies, masa enorme de obuses irritados, ya listos para nuestros futuros cañones-. iCobardes! iCobardes!... ¿Por qué esos gritos de gatos desollados vivos?... ¿ ¿Acaso temen que demos fuego a sus tugurios?... iTodavía no!... Por ahora, nos contentamos con hacer saltar en pedazos todas las tradiciones, como puentes podridos!... ¿La guerra?... Pues sí: ella es nuestra única esperanza, nuestra razón de vivir, inuestra única voluntad!... iSí, la guerra! Contra ustedes, que se mueren demasiado lentamente, y contra todos los muertos que atestan nuestras calles!

Como se puede constatar, Marinetti fue desde sus primeros escritos un leal discípulo de la máxima nietzscheana sobre «la transmutación de todos los valores de Occidente». En el texto titulado ¿̇ué es el futurismo?, firmado en 1920 por Emilio Settimelli, Mario Carli y su fundador, dividen el documento en tres partes para definir:

Es futurista en la vida: Aquel que ama la vida, la energía, la alegría, la libertad, el progreso, la valentía, la novedad, el sentido práctico, la velocidad... Los que actúan alegremente con la mirada siempre hacia el futuro, sin remordimiento, sin pedantería, sin falsa modestia, sin misticismo y melancolía ${ }^{38}$.

Es futurista en la política: Aquel que quiere abolir toda forma de parasitismo burocrático, industrial y capitalista... Aquel que ama y quiere toda la libertad con excepción de aquella del ser humano retrógrado, cobarde, parásito y antiitaliano ${ }^{39}$.

Es futurista en arte: Aquel que piensa y se expresa con originalidad, fuerza, vivacidad, entusiasmo, claridad, simplicidad, agilidad y síntesis... ${ }^{40}$.

Los autores dan preeminencia al pensamiento futurista en el arte ya que se asumen como representantes de la sensibilidad artística italiana. Advierten, sin embargo, que sufren la incomprensión y el hostigamiento de las mayorías por

37. EH, pp. 70 y 71 .

38. F. T. Marinetti, «Che cos'è il futurismo», en L. Caruso, Teoria e invenzione futurista, Milano: Mondatori, 2005, pp. 136 y 137.

39. Ibid.

40. Ibid. 
expresarse con un lenguaje evolucionado, que el hombre común no entiende, como tampoco comprende sus descubrimientos sorprendentes, ni la fuerza de sus expresiones polémicas, «ni los impulsos temerarios de sus intuiciones» ${ }^{41}$. La creación artística por lo tanto, es el resultado de la percepción del creador y es la representación del mundo, según las palabras de Schopenhauer. En la retórica del futurismo, no se concibe la idea pura ni la razón abstracta, ya que el sentimiento y el instinto son los elementos esenciales en el proceso de la representación artística.

El libro de Nietzsche que Marinetti consultó con avidez fue Así habló Zaratustra, obra «filosófico-poética» del mediodía de su pensamiento, como lo confirma Eugen Fink en su análisis sobre los conceptos del filósofo, ya liberado de las ideas de Schopenhaurer y del cientificismo positivista. Por el tema desarrollado en este ensayo, invertiremos el capitulado de la obra original, para concluir con la esencia del superhombre en las figuras protagónicas de los creadores de las vanguardias históricas italianas; ya que tanto De Chirico como Marinetti, si bien se identificaron con el nihilismo que se despliega en la cuarta parte de la obra, fueron esencialmente receptivos con la conciencia del ser superior y se asumieron con las cualidades del superhombre nietzscheano.

\section{LA VOLUNTAD DE PODER EN LOS MANIFIESTOS MARINETTIANOS}

La estética marinettiana tiene una gran deuda con la concepción de la voluntad de poder descrita por el filósofo alemán, pues el poeta y literato se identifica con la construcción e innovación de principios que logran la liberación de la vida humana, partiendo de los cimientos del ámbito terrenal hasta lograr la cumbre evolutiva con el perfil del superhombre. Marinetti presume de esta libertad de pensamiento y de acción desde la creación del manifiesto fundacional, al pretender penetrar en todos los espacios de la vida del hombre, por medio de la ecuación «arte-vida», emitiendo proclamas dirigidas al campo artístico y extraartístico, que abarcaban todas las artes, además de la política, la ciencia y la tecnología; en suma, todas las estructuras que configuraron la sociedad moderna.

Como ejemplo de su voluntad de poder, Marinetti secundó las premisas del filósofo alemán al intentar revolucionar y crear nuevos parámetros artísticos. En su «Manifiesto técnico de la literatura futurista», transforma toda la construcción literaria «heredada de Homero», con el fin de imitar la convención del tiempo y del espacio que han innovado los avances tecnológicos y científicos, como fue el aeroplano, para señalar la "posibilidad [del hombre] de volar como los ángeles»:

En el aeroplano, sentado sobre el tanque de gasolina, calentado mi vientre por la cabeza del aviador, sentí la inanidad ridícula de la vieja sintaxis heredada de Homero. iNecesidad furiosa de liberar las palabras, sacándolas de la prisión del período latino! iÉste tiene, naturalmente, como todos los imbéciles, una cabeza previsora, un vientre, dos piernas y dos pies planos, pero jamás tendrá dos alas!

41. Ibid. 
iApenas lo necesario para caminar, para correr un momento y detenerse casi de inmediato, resoplando!...42.

Marinetti, pues, concibe a la máquina y al aeroplano como las imágenes simbólicas de la modernidad. Así, su pensamiento crea un Olimpo ocupado por figuras mitopoéticas que representan nuevos valores culturales y a su creación la equipara con la perfección de la máquina, haciéndola partícipe de propiedades revolucionarias y vanguardistas, como es el caso de la hélice:

He aquí lo que me dijo la hélice vertiginosa, mientras corría a doscientos metros sobre las poderosas chimeneas de Milán. Y la hélice añadió: 1. Es necesario destruir la sintaxis... 2. Se debe usar el verbo en infinitivo, para que se adapte elásticamente al sustantivo... 3. Se debe abolir el adjetivo, para que el sustantivo desnudo conserve su color esencial... 4. Se debe abolir el adverbio, vieja hebilla que mantiene unidas entre sí las palabras... 5. Cada sustantivo debe tener su doble analógico... 6. Abolir también la puntuación... ${ }^{43}$.

Las enseñanzas de Zaratustra ilustran que el hombre superior, aunque intente persuadir al pueblo con la enseñanza de valores justos, puede engañarse a sí mismo presumiendo de un acto de generosidad desinteresada. Sin embargo, el filósofo corrige al hombre superior generador de ideas, develándole que no obstante sus buenas intenciones, sus actos son producto de la voluntad de poder; y dicta la siguiente sentencia: "Y quien tiene que ser un creador en el bien y en el mal: en verdad, ése tiene que ser antes un aniquilador y quebrantar valores. Por eso el mal sumo forma parte de la bondad suma: más ésta es la bondad creadora» ${ }^{44}$.

Marinetti pues, asumiendo su ser superior, sigue las enseñanzas nietzscheanas y en su "Manifiesto técnico de la literatura futurista» revoluciona la construcción literaria tradicional de Occidente, y recomienda:

En vista de que la velocidad aérea ha multiplicado nuestro conocimiento del mundo, la percepción por analogía se vuelve cada vez más natural para el hombre. Por ende, hay que suprimir el como, el tal cual, el así, el semejante a. Mejor aún, hay que fundir directamente el objeto con la imagen que dicho objeto evoca, presentando la imagen en escorzo mediante una sola palabra esencial ${ }^{45}$.

En «La más silenciosa de todas las horas», Nietzsche define la concepción del tiempo, y pone en boca de Zaratustra su falta de valor para trasmitir las reflexiones sobre el devenir del tiempo: «Entonces algo me habló de nuevo sin voz: 'Tienes que hacerte todavía niño y no tener vergüenza'». Para Fink, era la revelación sobre la esencia del tiempo, donde no hay diferencia entre pasado y futuro $^{46}$. Este pasaje esta nítidamente reflejado en el ensayo marinettiano: «Matemos el claro de luna».

42. F. T. Marinetti, «Manifiesto técnico de la literatura futurista», en O. Sáenz, El futurismo italiano, cit., pp. $163-170$

43. Ibid.

44. Za «De la superación de sí mismo», pp. 169-173.

45. F. T. Marinetti, «Manifiesto técnico de la literatura futurista», cit., pp. 163-170.

46. E. Fink, op. cit., pp. 115 y 116. 
Enrico Cavacchioli ${ }^{47}$ dormitaba y soñaba en voz alta:

—iYo siento rejuvenecer mi cuerpo de veinte años!... Y regreso, con pasos cada vez más infantiles, a mi cuna... iPronto volveré a entrar en el vientre de mi madre! iY por lo tanto, todo me está permitido!... iQuiero valiosos juguetes que romper... ciudades que aplastar, hormigueros humanos que trastornar! iQuiero domesticar los vientos y mantenerlos sometidos... Quiero un cambio de vientos, fluidos lebreros, para ir a la caza de los cirros flexibles y barbudos! ${ }^{48}$.

\section{REPUDIO POR LA POÉTICA FUTURISTA DEL «ETERNO RETORNO» NIETZSCHEANO}

El filósofo, después de negar la metafísica, de declarar la muerte de Dios y la inmortalidad del alma, se enfrenta al análisis del tiempo, con el fin de explicar la eternidad en el placer; idea que Nietzsche desarrolla en la tercera parte de Así habló Zaratustra. Para ello, rememora la filosofía clásica de Heráclito, la del «eterno retorno de las cosas». Nietzsche utiliza su intuición suprema para ir develando sus reflexiones sobre la esencia del tiempo. Para ello, Zaratustra «tiene que descender al dolor» más agudo que jamás haya sufrido. Allí se hace una pregunta medular: «‘¿De dónde vienen las montañas más altas?’, pregunté en otro tiempo. Entonces aprendí que vienen del mar. Este testimonio está escrito en sus rocas y en las paredes de sus cumbres. Lo más alto tiene que llegar a su altura desde lo más profundo $»^{49}$. En el capítulo «De la visión y del enigma», el filósofo expresó por primera ocasión la figura del «eterno retorno». Para explicar el sentido de la infinitud del tiempo utiliza la metáfora del enano, quien libera al profeta del «espíritu de la pesantez», y al pastor, que traga una serpiente de la que se libera desprendiendo de una mordida su cabeza: «Lejos de sí escupió la cabeza de la serpiente - y se puso de pie de un salto... iun transfigurado, iluminado, que reía! Nunca antes en la tierra había reído hombre alguno como él rió! $\aleph^{50}$. El hombre trasfigurado, el superhombre advirtió sobre la eternidad del tiempo pasado y del tiempo futuro. En este transcurrir del tiempo, los hechos que ya trascurrieron vuelven a sucederse dentro de la eternidad del tiempo.

Esta definición de tiempo nietzscheano, al conceder que se hayan realizado toda clase de eventos en el pasado, quedará un tiempo indefinida por delante, y entonces volverá a iniciar el ciclo, y así indefinidamente. Todos los acontecimientos que se sucedan en el mundo se repetirán sin pausa ni concierto. Todo volverá eternamente en el mencionado ciclo, aun los eventos perversos y aniquilantes para el ser humano. Respecto a esta definición del tiempo, el filósofo, lejos de determinar un infinito caos en la vida de la humanidad, señala que el hombre tiene la libertad de superación al transmutar todos los valores para alcanzar la perfección del superhombre.

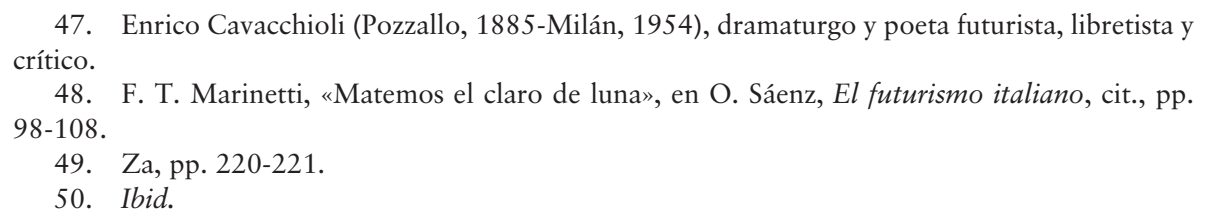


No obstante que en la retórica futurista encontramos una fuerte inspiración de la filosofía irracional, el punto en discordia de Marinetti y sus partidarios fue precisamente la valoración que Nietzsche le dio al tiempo y al «eterno retorno», definición que le valió el calificativo de filósofo "pasadista», secuestrado por el pasado clásico griego:

En nuestra lucha contra la pasión profesoral del pasado, nosotros renegamos violentamente del ideal y la doctrina de Nietzsche.

Me interesa aquí demostrar que la crítica se ha engañado del todo, al considerarnos como unos nuevos nietzscheanos. En efecto, bastará que consideren la parte constructiva de la obra del gran filósofo alemán, para convencerse de que su Superhombre, generado en el culto filosófico de la tragedia griega, supone en su padre un retorno apasionado hacia el paganismo y la mitología. Nietzsche seguirá siendo, pese a todos sus ímpetus hacia el porvenir, uno de los más encarnizados defensores de la grandeza y de la belleza antigua.

Es un pasadista que camina osadamente en las cumbres de los montes tesálicos, con los pies malhadadamente entorpecidos por largos textos griegos ${ }^{51}$.

Los futuristas, así, lejos de voltear al pasado en una espiral sin fin, propusieron la evolución mental y física de las máquinas con «una verdadera sensibilidad». De ahí que el hombre se tenga que identificar con el motor, para facilitar y perfeccionar «un intercambio incesante de intuición, de ritmo, de instinto y de disciplina metálica, absolutamente ignorado por la mayoría y solamente adivinado por los espíritus más lúcidos» ${ }^{52}$.

Este prototipo del nuevo hombre, imitaría a la máquina «en el cual serán abolidos el dolor moral, la bondad, el afecto y el amor, los únicos venenos corrosivos de la inagotable energía vital, únicos interruptores de nuestra potente electricidad fisiológica». De este modelo conceptual surgió el maniquí tanto en la poética metafísica como en la futurista: un ser ensamblado con diversos artefactos a imagen de la máquina. Dentro del inventario de la industria mecánica, será el aeroplano el que conciban con la perfección del numen en el nuevo panteón vanguardista.

Nietzsche distinguió entre la moral de los señores y la moral de los esclavos: la de los primeros es la de los seres implacables, de los poderosos; es la moral de los impulsos vitales. De esta moral de los señores se transitará al «tipo no humano y mecánico, construido con una velocidad omnipresente, será naturalmente cruel, omnisciente y combativo». El filósofo exaltó con vehemencia la guerra como la ocasión perfecta para que se fortalezcan los valores superiores y la valentía. La moral de los señores ayudará a que exteriorice su voluntad, «de modo que ella se prolongue hacia fuera de él como un inmenso brazo invisible, el Sueño, y el Deseo, que hoy son palabras vanas, reinarán soberanos sobre el Espacio y sobre el tiempo domados». En contraste, la moral de los esclavos es la de los seres débiles, vulnerables y degenerados; es una moral de pusilánimes, que se rigen por la moral cristiana.

Como máxima del futurismo, Marinetti presagia:

51. F. T. Marinetti, «Contra los profesores», en O. Sáenz, El futurismo italiano, cit., pp. 133136.

52. F. T. Marinetti, «El hombre multiplicado y el reino de la máquina», en O. Sáenz, El futurismo italiano, cit., pp. 129-132. 


\begin{abstract}
Nosotros creemos en la posibilidad de un número incalculable de transformaciones humanas, y declaramos sin sonreír que en la carne del hombre duermen unas alas... Podemos prever desde ahora un desarrollo a manera de proa de prominencia externa del esternón, que será tanto más considerable, cuanto que el hombre futuro se volverá cada vez un mejor aviador. Un desarrollo análogo se nota precisamente, entre los pájaros, en los mejores voladores ${ }^{53}$.
\end{abstract}

\title{
6. EL NIHILISMO ES DERROTADO POR LA VELOCIDAD FUTURISTA
}

La etapa del nihilismo llega a la estación de Occidente después de destruir la filosofía metafísica, la religión y la moral del cristianismo; este proceso de aniquilación se encuentra al interior de cada una de estas estructuras, ya que no necesita un factor externo para su propio desenmascaramiento y su destrucción final; a este proceso, Nietzsche le llamó nihilismo, «la nada». Respecto a este sentimiento de orfandad del hombre, al no saber ni su destino ni su fin, el filósofo comenta que sólo es un periodo transitorio, que se remontará cuando el hombre se conecte al todo cósmico; esta toma de conciencia del hombre le otorgará su libertad y la plena realización de su propio ser.

Los futuristas encuentran la comunión con el todo, después del periodo nihilista, en la fuerza de la velocidad. En el manifiesto futurista de 1913, denominado Las analogías plásticas del dinamismo, se subraya la importancia fundamental de la velocidad para expresar en arte sus sensaciones de movimiento.

La velocidad nos ha dado una nueva noción del espacio y del tiempo y por consiguiente de la vida misma, nada más lógico que nuestras obras futuristas caractericen todo el arte de nuestra época con la estilización del movimiento que es una de las manifestaciones más inmediatas de la vida ${ }^{54}$.

Al ser la velocidad el arquetipo y el tema príncipe en la poética futurista, Marinetti le dedicó una extensa literatura al tema. En el manifiesto La nueva religiónmoral de la velocidad, donde nos recuerda su veneración por la misma desde el manifiesto fundacional, declara la existencia de una belleza nueva: la belleza de la velocidad.

Al respecto, reflexiona que la moral cristiana limitó de manera prejuiciosa al hombre de los excesos de la sensualidad y moderó sus instintos. En esta nueva estación, «la energía humana centuplicada por la velocidad dominará el Tiempo y el Espacio». Además que, «la velocidad da por fin a la vida humana una de las características de la divinidad: la línea recta».

Dentro de la axiología futurista, el autor distingue las cualidades positivas de la velocidad, la que contrasta con la lentitud y pasividad:

La velocidad, teniendo por esencia la síntesis intuitiva de todas las fuerzas en movimiento, es naturalmente pura. La lentitud, teniendo por esencia el análisis racional de todos los cansancios en reposo, es naturalmente inmunda. Después de la destrucción del antiguo bien y el antiguo mal, nosotros creamos un nuevo bien: la velocidad, y un nuevo mal: la lentitud.

53. Ibid., pp. 129-132.

54. F. T. Marinetti, «Las analogías plásticas del dinamismo», en O. Sáenz, El futurismo italiano, cit., pp. 217- 223. 
Para Marinetti, el correr a gran velocidad es una oración que se equipara al acto de orar para comunicarse con la divinidad. Dentro de su megalomanía, recomienda venerar a la rueda y a los rieles para adorar a la divina velocidad. Después de citar los lugares habitados por lo divino, que son las estructuras materiales que se han transformado con base en los avances científicos y tecnológicos, y que han subvertido el tiempo y el espacio del hombre moderno, el autor ofrece al hombre de Occidente, esencialmente al pueblo italiano belicista (1916), la inmortalidad, con la fuerza de la velocidad. «Tan solo la velocidad podrá matar el venenoso Claro-de-luna, nostálgico, sentimental, pacifista y neutral. iItalianos! Sean veloces y serán fuertes, optimistas, invencibles, inmortales».

\section{LA ASUNCIÓN DEL «SUPERHOMBRE» EN MARINETTI Y EN DE CHIRICO}

«-Y una vez más Zaratustra se abismó dentro de sí y volvió a sentarse sobre la gran piedra y reflexionó. De repente se levantó de un salto,

iCompasión! iLa compasión por el hombre superior!, gritó y su rostro se endureció como el bronce. iBien! iEso - tuvo su tiempo!

Mi sufrimiento y mi compasión — iqué importan!

¿Aspiro yo acaso a la felicidad? iYo aspiro a mi obra!»

Friedrich Nietzsche ${ }^{55}$

Nietzsche, en la figura de Zaratustra, está satisfecho de haber colaborado con la toma de conciencia de los «seres superiores», que asimilan y aprenden a vivir sin Dios, y que se liberan de la moral opresora de Occidente. Para los iniciados, este proceso, no obstante su valor trascendente, no dejaba de ser doloroso. El autor lo representa como «los hombres de la gran náusea», que no soportan la enajenación que produce el tumulto inconsciente e ignorante conformado por los hombres comunes. La toma de conciencia del «hombre superior» nietzscheano la asumió Filippo Tommaso Marinetti y los artistas que se identificaron con la vanguardia histórica, quienes al proclamar la poética futurista, no dejaron de estar sujetos a la marginación por una virulenta oposición, causando una fuerte confrontación entre la población italiana y europea en general, descalificándolos por provocadores y desquiciados que polarizaban a la sociedad moderna en su conjunto. En el manifiesto Contra los profesores, aseguraron que llegaría el momento de defender sus ideas no sólo con bofetadas y puñetazos, sino con «el atentado», en defensa del pensamiento, de la creación artística y contra «la costra glorificada». Debo agregar que por todas estas buenas razones nosotros no somos amados por los magistrados. Los policías nos vigilan, los curas se hacen a un lado a nuestro paso, y los socialistas nos odian cordialmente. Nosotros devolvemos a todos ellos este odio y este desprecio, porque en ellos despreciamos a unos representantes indignos de ideas puras y no terrenales, como la Justicia, la Divinidad, la Igualdad y la Libertad $^{56}$.

55. Za, pp. 430-433.

56. F. T. Marinetti, «Contra los profesores», cit., pp. 133-136. 
Para la tradición occidental, no dejaba de sorprender el desplazamiento de los valores tradicionales por nuevos patrones ideológicos que los futuristas denominaron: la modernolatría, neologismo que encierra la multiplicidad de factores culturales, tanto científicos como humanísticos, que creó la vanguardia histórica en la era moderna. Umberto Boccioni utilizó el neologismo para definir «los estados de ánimo plásticos», que resumen la expresión plástica y expresionista de todos los tiempos. Debería ser la fusión perfecta entre «la impasible potencia plástica [que emana de la pintura pura] y la expresión del problema lírico de la conciencia, completamente renovada e interpretada como exponente absoluto de la MODERNOLATRÍA» ${ }^{57}$. La modernolatría, como doctrina de vida, fue representada con sonidos estridentes de tambores de guerra en «Matemos el claro de luna», pieza literaria clave en el estadio temprano del futurismo:

-iHurra! Finalmente somos dignos de comandar el gran ejército de los locos y las fieras desencadenadas!... iHurra! iNosotros dominamos nuestra retaguardia: el Océano, con su envoltura de espumeantes caballerías! iAdelante, locos, locas, leones, tigres y panteras!... iAdelante, escuadrones de oleadas!... iNuestros aeroplanos serán para ustedes, una vez banderas de guerra y otra amantes apasionadas! Deliciosas amantes, que nadan, con los brazos abiertos, sobre las ondas de los follajes, o que se entretienen blandamente, en el columpio de la brisa!... ${ }^{58}$.

La concepción de "genio», de «hombre superior», fue también asumida por Giorgio de Chirico y los artistas que comulgaron con su creación pictórica. Basta recordar que la clarividencia metafísica sólo fue concedida —-según sus propugnadores- a los seres con atributos superiores que pudieran sustraerse del estadio físico para observar la «segunda apariencia de las cosas», la visión metafísica. En Zeus el explorador, De Chirico invita a la «marcha» o peregrinaje hacia la nueva metafísica:

Como los frutos otoñales, hoy estamos maduros para la nueva metafísica.

Vengan los soplos potentes de allende los mares inquietantes.

Llegue nuestro llamado a las ciudades populosas de los lejanos continentes.

$\mathrm{Ni}$ tampoco debemos engordar en la felicidad de nuevas creaciones.

Seamos exploradores prestos para nuevas partidas.

Bajo los techos llenos de ecos de choques metálicos los cuadrantes son

tocados por el signo de la separación.

En las pequeñas casas bardeadas las campanillas vibran.

Es la hora...

«iSeñores, en marcha! ${ }^{59}$.

Zaratustra declaró: «Ésta es mi mañana, mi día comienza: iasciende, pues, asciende tú, gran mediodía!».

Nietzsche concluyó: «Así habló Zaratustra, y abandonó su caverna, ardiente y fuerte como un sol matinal que viene de oscuras montañas ${ }^{60}$.

57. U. Boccioni, Pintura e scultura futuriste (Dinamismo plastico), ed. de Z. Birolli, Milano: Saggi e documenti del novecento, 1997, p. 155.

58. F. T. Marinetti, «Matemos el claro de luna», cit., pp. 98-108.

59. G. de Chirico, «Zeus el explorador», en O. Sáenz, Giorgio de Chirico, cit., pp. 102 y 103.

60. Za, pp. 430-433. 